\title{
Anti-inflammatory cytokines in cystic fibrosis lung disease
}

\author{
V. Starosta*, F. Ratjen\# ${ }^{\#}$ E. Rietschel ${ }^{\mp}$, K. Paul $^{+}$and M. Griese*
}

ABSTRACT: Lung inflammation plays a pivotal role in the pathogenesis of airway disease in cystic fibrosis (CF). An imbalance between pro- and anti-inflammatory mediators has been observed and a deficiency in the anti-inflammatory response has been proposed, but this concept remains controversial.

In the present study, the concentrations of two anti-inflammatory mediators, lipoxin $A\left(L_{x} A_{4}\right)$ and Clara cell protein 10 (CC-10), were assessed in bronchoalveolar lavage fluid (BALF) of CF patients with a wide range of endobronchial inflammation and disease controls with neutrophilic inflammation unrelated to CF.

No differences were observed in LXA $\mathrm{A}_{4}$ BALF concentrations between CF patients and controls with a similar degree of neutrophilic airway inflammation. Concentrations were also similar in CF patients with mild versus more severe airway inflammation. In contrast, CC-10 concentrations were lower in CF patients, but this decrease was limited to patients with more intense airway inflammation.

The present data do not support the concept of a primary defect in anti-inflammatory mediators in cystic fibrosis lung disease. Although Clara cell protein concentrations were found to be reduced, these alterations appear to be secondary to neutrophilic airway inflammation rather than due to a primary deficiency.

KEYWORDS: Clara cell protein, cystic fibrosis, inflammation, lipoxin

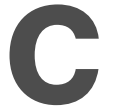
ystic fibrosis (CF) lung disease is characterised by depletion of the airway surface liquid resulting in mucus retention, chronic bacterial airway infection and inflammation. Inflammation occurs very early and is more intense in CF than in non-CF patients with a similar bacterial load [1]. Neutrophils are recognised to play a central role by releasing proinflammatory mediators, such as reactive oxygen species and proteolytic enzymes. An imbalance has been proposed between pro- and antiinflammatory mediators, and some studies have suggested a deficiency in the anti-inflammatory response $[2,3]$. Whether this is a primary event inherent to CF lung disease or is the consequence of neutrophilic inflammation has not been clarified.

In a recent study, lipoxin $\mathrm{A}_{4}\left(\mathrm{LxA}_{4}\right)$, a substance with anti-inflammatory properties, was described to be decreased in CF airways [4]. Lipoxins constitute the first recognised class of endogenous anti-inflammatory lipid-based autacoids that function as endogenous "stop signals" to downregulate or counteract the formation and actions of pro-inflammatory mediators [5]. Lipoxins (lipoxygenease interaction products) are endogenous anti-inflammatory mediators that also promote resolution of inflammation in vivo. Lipoxin generation has been demonstrated in a variety of human and experimental inflammatory, hypersensitivity and vascular diseases [6]. While the preliminary evidence suggests a relative deficiency of $\mathrm{LxA}_{4}$ in $\mathrm{CF}$ airways, the group of CF patients included in that study [4] was small, and subgroup analysis was therefore not feasible to define whether lipoxin deficiency is a common feature in CF lung disease or whether it is present only in patients with intense neutrophilic inflammation.

Bronchial epithelial cells produce another compound with potential anti-inflammatory properties, the Clara cell protein 10 (CC-10) [7]. CC-10 is also known as uteroglobin or urine protein-1 and it is produced by nonciliated bronchial epithelium. Human CC-10 exhibits high homology with rabbit uteroglobin, which has multiple activities, including immunosuppressive, anti-inflammatory, antiproteinase, and antiphospholipase $\mathrm{A}_{2}$ activities, suggesting that $\mathrm{CC}-10$ might play a role in anti-inflammatory responses [7, 8]. CC-10deficient mice demonstrate more severe inflammation than wild-type controls [9]. Lastly, CC-10

\section{AFFILIATIONS}

*Lung Research Group, Children's Hospital of Ludwig Maximilians University, Munich, ${ }^{*}$ Dept of Paediatrics, University of Essen, Essen,

-Dept of Paediatric Pneumology and Allergology, Children's Hospital, University of Cologne, Cologne, and ${ }^{+}$Dept of Paediatric Pneumology and Immunology, Charité, HumboldtUniversity, Berlin, Germany.

CORRESPONDENCE

M. Griese

Children's Hospital

Ludwig Maximilians University Lindwurmstr. 4

80337 Munich

Germany

Fax: 498951607872

E-mail: matthias.griese@med.unimuenchen.de

Received:

June 172005

Accepted after revision:

June 062006

\section{SUPPORT STATEMENT}

M. Griese, K. Paul, F. Ratjen and E. Rietschel are members of the Bronchoalveolar lavage for the Evaluation of Anti-inflammatory Treatment (BEAT) study group. 
appears as one of the most abundant respiratory tract-derived proteins, making up $\sim 7 \%$ of the total protein content of lung lavages from healthy nonsmokers [10]. CC-10 has been proposed to function as an anti-inflammatory agent, based on its ability to inhibit the activation of phospholipase A2 (PLA2), a key enzyme involved in the production of prostaglandins and other eicosanoids, as well as possessing antifibrotic activity [11, 12]. As yet, no information is available about CC-10 concentrations in airways of patients with CF.

In the present study, concentrations of both CC-10 and $\mathrm{LxA}_{4}$ were assessed in a group of CF patients with a wide range of endobronchial inflammation as well as disease controls. It was hypothesised that there is no absolute, constitutive deficiency of $\mathrm{LxA}_{4}$ and CC-10 in CF, but the lack of these substances may appear during pronounced chronic inflammation of the lungs. It was reasoned that if a defect in these anti-inflammatory mediators was specific for CF, it should be seen in CF patients with different degrees of airway inflammation and should not be seen in control subjects with airway inflammation unrelated to $\mathrm{CF}$.

\section{MATERIALS AND METHODS}

Subjects, bronchoalveolar lavage and sample preparation

To test the above-indicated hypothesis, all available bronchoalveolar lavage fluid (BALF) samples were used from the following two previous studies in CF patients. 1) The Bronchoalveolar lavage for the Evaluation of Antiinflammatory Treatment (BEAT) study, which had investigated inflammation in CF patients with normal lung function (forced expiratory volume in one second (FEV1) $>80 \%$ predicted), and 2) the Glutathione (GSH) study, a study that included CF patients with FEV1 50-80\% pred; these samples were included to obtain a broader range of disease activity [13, 14]. All these samples represented the whole CF group. Cellfree supernatant of BALF was analysed from 69 patients with CF. BALF from 14 subjects with chronic bronchitis was obtained during diagnostic work-up. Bronchoalveolar lavage (BAL) was performed in the lingula or middle lobe [15]. The return from the first fraction was retained separately from the other three fractions, which were pooled. Fractions $2-4$ were filtrated via sterile $160-\mu \mathrm{m}$ gauze, and protease inhibitors $0.5 \mathrm{mM}$ EDTA, $500 \mu \mathrm{M}$ Pefablock (Merck, Darmstadt, Germany), $5 \mu \mathrm{M}$ E-64 and $50 \mu \mathrm{M}$ bestatin (both from Roche, Basel, Switzerland) were added to aliquots and centrifuged to remove cells. All manipulations were performed immediately on ice. Aliquots of the cell supernatant were stored at $-80^{\circ} \mathrm{C}$ prior to analysis. Duration of storage ranged 3-5 yrs and was the same for the two study groups. To avoid problems associated with a potential instability of $\mathrm{LxA}_{4}$ from repetitive freeze-thaw cycles, aliquots of the lavages were used that had not been previously thawed.

CF was diagnosed by means of a positive (chloride $>60 \mathrm{mM}$ ) sweat test in each case. Additionally, the most frequent 30 mutations were searched for. Chronic bronchitis was defined by the presence of long-term ( $>3$-month duration) respiratory tract symptoms, such as intermittent rhonchi, coarse crackles, and continuous dry or productive cough [16, 17]. These findings were not associated with bronchiectasis on computed tomography scans. None of the children had gross structural airway abnormalities or primary ciliary dyskinesia (excluded by bronchoscopy and nasal or bronchial biopsy (beat frequency and pattern, electron microscopy of cilia)), CF (excluded by negative sweat testing (chloride concentration $<40 \mathrm{mM}$ )), passive or active smoke exposure (by history), immune deficiency (normal immunoglobulins, complement system, granulocyte function, $\mathrm{T}$ - and B-cell numbers and functions), or gastro-oesophageal reflux disease (two-point $\mathrm{pH}$ probe testing, BAL lipid-laden macrophages, upper gastrointestinal tract series). Asthma was not the principal diagnosis because neither history of atopy, wheezing or eosinophils were a finding in these children. The clinical characteristics of the patients' groups are given in the tables 1 and 2 .

The study protocols were approved by the institutional review boards. Approval for the usage of the samples was given by the Ethics Committee of the University of Munich (Munich, Germany). Written informed consent was obtained from adult subjects, parents of the children and those children old enough before the original BEAT and GSH studies.

\section{Biochemical analysis}

$\mathrm{LxA}_{4}$ concentrations were measured by ELISA (Oxford Biomedical Research, Oxford, MI, USA) according to the manufacturer's instructions. Briefly, $\mathrm{LxA}_{4}$ was extracted from $500 \mu \mathrm{L}$ of BALF via Sep-Pak C18 light cartridges (Waters, Eschborn, Germany); solvent was evaporated under a gentle stream of nitrogen and the remainder was immediately dissolved in sample buffer and subjected to ELISA. LxA

\begin{tabular}{|c|c|c|}
\hline \multirow[t]{2}{*}{ TABLE 1} & \multicolumn{2}{|c|}{$\begin{array}{l}\text { Clinical characteristics and bronchoalveolar } \\
\text { lavage cytology of the whole group of cystic } \\
\text { fibrosis (CF) patients }\end{array}$} \\
\hline & & Whole CF group \\
\hline \multicolumn{2}{|l|}{ Subjects $n$} & 69 \\
\hline \multicolumn{2}{|c|}{ Age yrs } & $14.5(3.7-37.7)$ \\
\hline \multicolumn{2}{|c|}{ Macrophages \% } & $40.8(1.6-96.5)$ \\
\hline \multicolumn{2}{|c|}{ Lymphocytes \% } & $7.0(0.0-45.2)$ \\
\hline \multicolumn{2}{|c|}{ PMN \% } & $45.3(1.0-96.0)$ \\
\hline \multicolumn{2}{|c|}{ Eosinophils \% } & $0.4(0.0-15.0)$ \\
\hline \multicolumn{2}{|c|}{ FEV $1 \%$ pred } & 88.7 (52.0-128.4) \\
\hline \multicolumn{2}{|c|}{ Total cell count $\times 10^{4} \mathrm{~mL}^{-1}$} & $34.35(0.4-974.0)$ \\
\hline \multicolumn{2}{|c|}{ Neutrophils $\times 10^{4} \mathrm{~mL}^{-1}$} & $10.9(0.04-935.0)$ \\
\hline \multicolumn{2}{|c|}{ CFTR dF 508 homozygous } & $47 / 53^{\#}$ \\
\hline \multicolumn{2}{|c|}{ Pseudomonas aeruginosa } & $40 / 59^{\circ}$ \\
\hline
\end{tabular}

Data are presented as median (range), unless otherwise indicated. PMN: polymorphonuclear granulocytes; FEV1: forced expiratory volume in one second; \% pred: \% predicted; CFTR dF 508: cystic fibrosis transmembrane regulator protein with mutation $\mathrm{dF} 508$. ${ }^{*}$ : A number of patients with CFTR $\mathrm{dF}$ 508 mutations only is shown. The first number indicates the number of positive results and the second, the number of available data. Some patients had other CFTR mutations or mutations that were not included in the screen. " Number of patients where $P$. aeruginosa was found in bronchoalveolar lavage. Chronic infection with $P$. aeruginosa was defined by the presence of $P$. aeruginosa in at least three quarterly sputum or throat cultures during the last year. The first number indicates the number of subjects with positive results and the second, the number of available subjects. 


\section{TABLE 2 Clinical characteristics of compared patient groups}

\begin{tabular}{|c|c|c|c|}
\hline Subjects $n$ & 37 & 14 & \\
\hline Macrophages \% & $58.2(4.0-96.5)$ & $78.5(5.0-92.0)$ & NS \\
\hline Lymphocytes \% & $7.0(0.0-45.2)$ & $10.0(1.0-35.0)$ & NS \\
\hline Neutrophils \% & $30.5(1.0-92.0)$ & $3.0(1.0-91.0)$ & 0.03 \\
\hline Neutrophils $\times 10^{4} \mathrm{~mL}^{-1}$ BALF & $5.15(0.038-718.6)$ & $1.18(0.054-86.9)$ & NS \\
\hline
\end{tabular}

recovery after the extraction procedure was $60 \pm 5 \%(n=8)$, as estimated by high-pressure liquid chromatography. Interassay coefficient of variation was 16.4 and $21.6 \%$ for standard and samples, respectively. Spiking experiments of lavages revealed no difference between $\mathrm{CF}$ and bronchitis samples.

CC-10 was analysed by one-dimensional electrophoresis performed on $10 \%$ bis-Tris NuPAGE gels (Invitrogen, Carlsbad, CA, USA). Protein $(5 \mu \mathrm{g})$ from BALF samples was electrophoretically separated under reducing and denaturing conditions. One standard sample was run on all gels in order
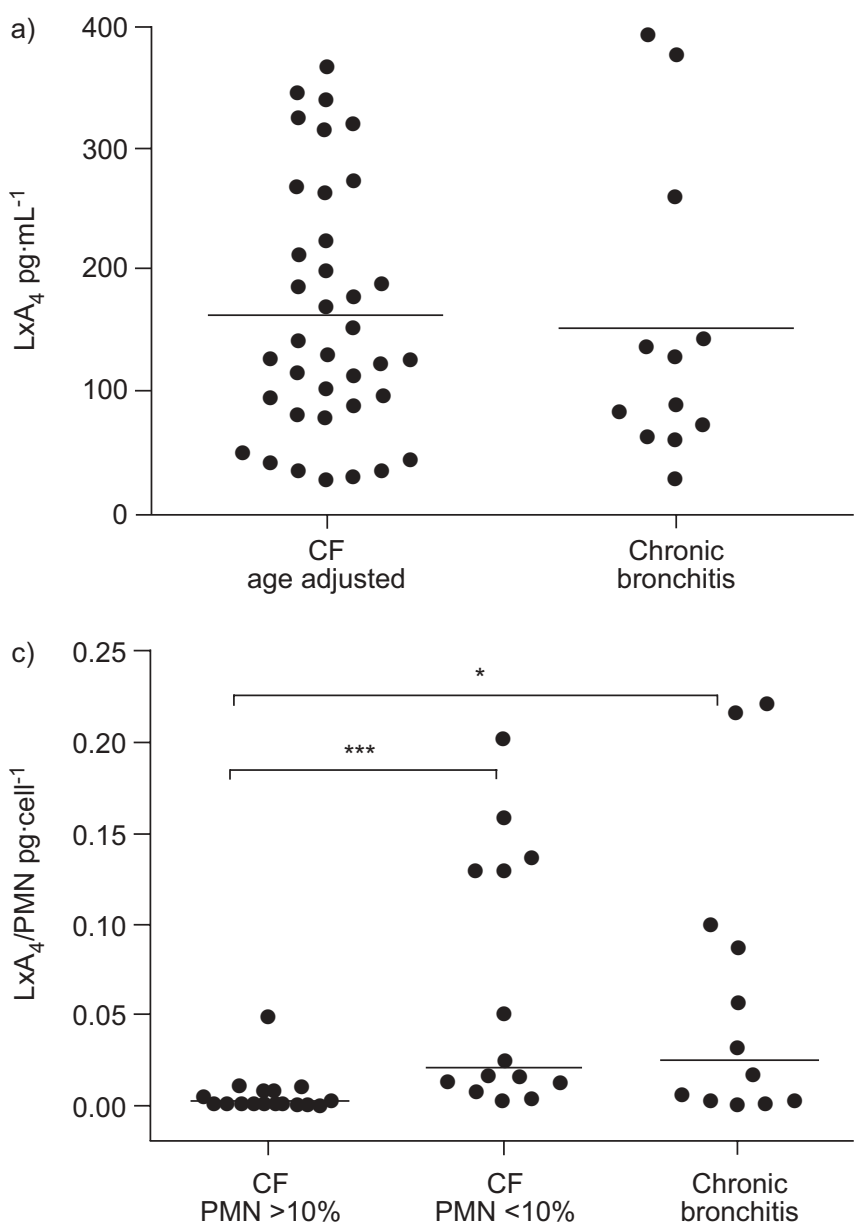

to allow a valid comparison among the different gels. After blotting on polyvinylidene fluoride membrane (Millipore, Bedford, MA, USA) and blocking with 3\% fish gelatine in Tris-buffered saline, the membrane was incubated with antiurine protein-1 antibodies (1:40,000; Dako A/S, Glostrup, Denmark) overnight at $4^{\circ} \mathrm{C}$. After 1-h incubation with secondary antibodies, the blots were developed with electrochemiluminescence detection reagent (Amersham Biosciences, Uppsala, Sweden) and the intensity of the bands was quantified by densitometry (Quantity one; Bio-Rad, Hercules, CA, USA). Interassay coefficient of variation was $11 \%$.

b)

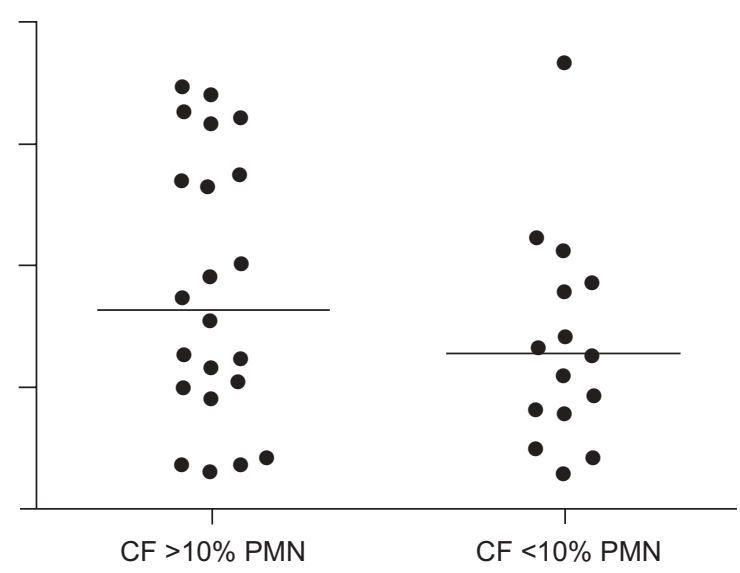

FIGURE 1. Lipoxin $A_{4}\left(L_{X A}\right)$ content in bronchoalveolar lavage fluid (BALF). No significant differences between the group of the age-adjusted cystic fibrosis (CF) patients and the disease control group with chronic bronchitis (a), as well as no differences within subgroups of the age-adjusted CF patients with high $(>10 \%)$ and low $(<10 \%)$ relative polymorphonuclear granulocytes (PMN) count in BALF (b), were shown by the Mann-Whitney U-test. c) The LXA 4 /PMN ratio was significantly lower in the subgroup of CF patients with high (>10\%) relative PMN count in BALF (Kruskal-Wallis test with Dunn's post hoc test). Samples with values of $697,810,2294,671$ and $630 \mathrm{pg} \cdot \mathrm{mL}^{-1}$ were considered as outliers and were excluded from the graph. ${ }^{*}: p<0.05$; ${ }^{* \star}: p<0.001$ (all in the CF patients). 

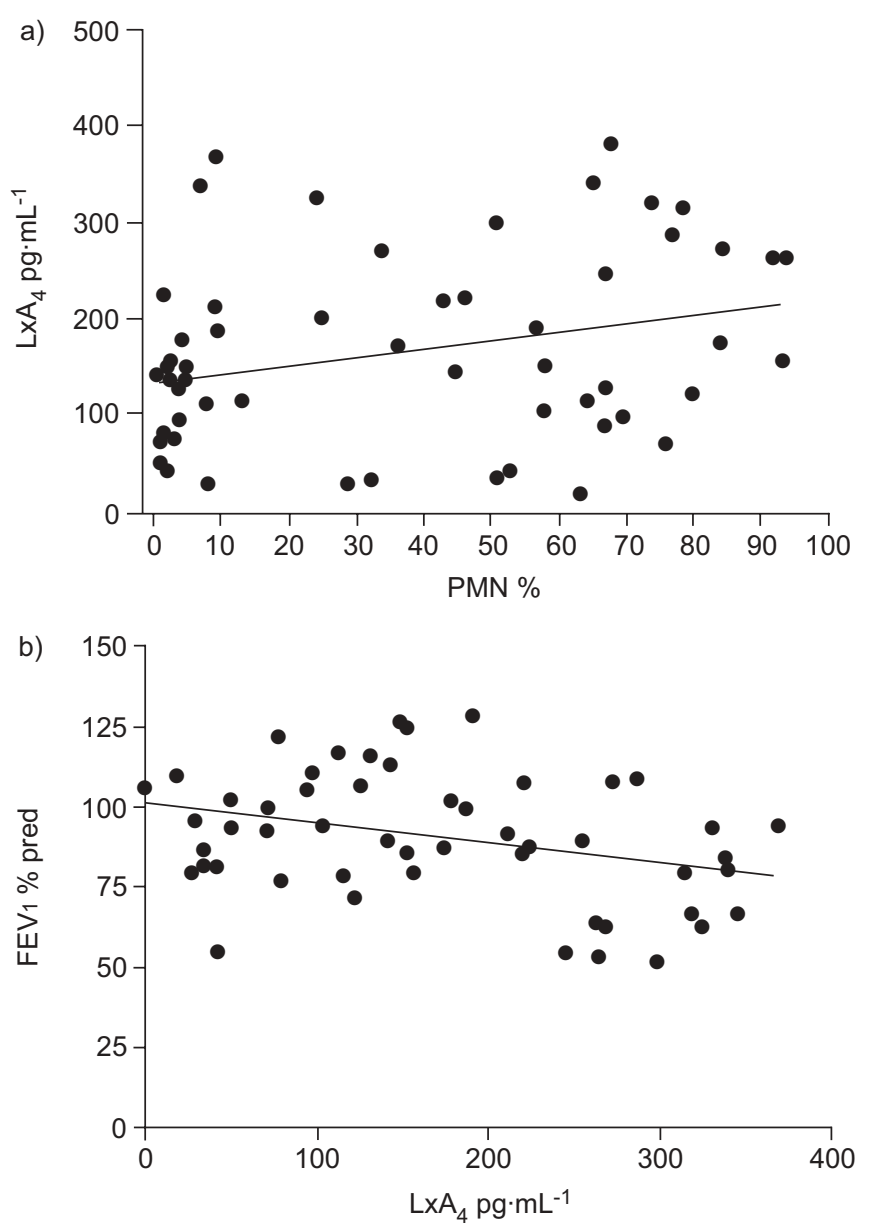

FIGURE 2. Correlations within whole group of cystic fibrosis (CF) patients. a) Significant positive correlation between lipoxin $\mathrm{A}_{4}\left(\mathrm{LXA}_{4}\right)$ concentration and relative polymorphonuclear granulocytes (PMN) count in bronchoalveolar lavage fluid (BALF) was found. b) Negative correlation was observed between $L X A_{4}$ concentration and lung function in CF patients (Spearman rank sum correlation test). Samples with values 697, 810, 2294, 671 and $630 \mathrm{pg} \cdot \mathrm{mL}^{-1}$ with a relative PMN count in BALF of $57,19,96,80$ and $20 \%$, respectively, were considered as outliers and were excluded from the graph. With inclusion of these values, the correlation a) between $\mathrm{LXA}_{4}$ concentration and relative PMN count in BALF was $r=0.36, p=0.006$ (without outliers: $r=0.32, p=0.02$ ); and $b$ ) between $L_{X A}$ concentration and lung function correlation was with $r=-0.4, p=0.002$ (without outliers $r=-0.29, p=0.039$ ). FEV1: forced expiratory volume in one second; \% pred: \% predicted.

\section{Statistical analysis}

Two groups were compared by Mann-Whitney U-test and three groups by Kruskal-Wallis test with Dunn's post hoc test. Data are given as median values together with their range. Correlation analysis was performed by Spearman rank sum test and by calculation of linear regression lines. These analyses were primarily carried out in the whole group of CF patients. A p-value $<0.05$ was considered significant. The CF group as a whole was much larger and skewed towards older subjects, compared with the group of children with chronic bronchitis. Therefore, to perform comparisons, the age of the two groups was adjusted by a systematic procedure. From the CF group, the oldest patients were removed stepwise in order to avoid a selection bias (one step $=1 \mathrm{yr}$ ), until the two groups had a comparable age that did not differ significantly. Thus, an upper cut-off value for age of 16 yrs was obtained and consistently used for all comparisons of the two groups.

This subgroup of CF patients did not differ in age and sex from the comparison group of subjects with chronic bronchitis. These age-adjusted CF patients were also subdivided into two groups according to their percentage of neutrophils in BAL (elevated $(>10 \%)$ versus normal $(<10 \%)$ ).

\section{RESULTS Lipoxin}

The concentration of $\mathrm{LxA}_{4}$ in BALF of the age-adjusted group of patients with CF did not differ from its concentration in the group of children with chronic bronchitis (fig. 1a). The ageadjusted CF group was divided into patients with pronounced and mild inflammation in the lungs (relative polymorphonuclear granulocytes (PMN) count in BALF $>10 \%$ and $<10 \%$ accordingly). No significant differences among these groups in $\mathrm{LxA}_{4}$ BALF content were found (fig. 1b). The concentration of $\mathrm{LxA}_{4}$ related to $\mathrm{PMN}$ burden (the $\mathrm{LxA}_{4} / \mathrm{PMN}$ ratio) was lower in CF patients with a high PMN count in BALF, i.e. PMN $>10 \%$ (fig. 1c) compared with CF patients with low PMN and also with the control group of subjects with bronchitis. In the whole group of CF patients, $\mathrm{LxA}_{4}$ was positively correlated to total cell count $(\mathrm{r}=0.41, \mathrm{p}=0.001)$, absolute $(\mathrm{r}=0.46, \mathrm{p}<0.001)$ and relative $(r=0.32, \quad p=0.02) \quad P M N$ counts. $\mathrm{LxA}_{4}$ correlated negatively with FEV1 $(r=-0.29, p=0.039$; fig. 2).

\section{Clara cell protein}

The content of CC-10 in BALF of the CF patients studied was significantly lower than in the comparable control group (fig. 3a). The lowest CC-10 values were observed in the $\mathrm{CF}$ patients with a relative PMN count in BALF of $>10 \%$ (fig. 3b). In addition, the CC-10/PMN ratio was significantly lower in this group of patients (fig. 3c). In the whole group of $\mathrm{CF}$ patients, the content of CC-10 in BALF correlated negatively with total cell count $(\mathrm{r}=-0.34, \mathrm{p}=0.024)$, absolute $(\mathrm{r}=-0.5$, $\mathrm{p}=0.001)$ and relative $(\mathrm{r}=-0.38, \mathrm{p}=0.013)$ PMN counts (fig. 4). Only a marginal correlation between FEV1 and CC-10 was found in the whole group of CF patients $(r=0.33, p=0.033$; fig. $4 \mathrm{~b}$ ). Analysis of Western blots revealed no proteolytic fragments of CC-10.

\section{DISCUSSION}

In the present study, the BALF content of CC-10 and $\mathrm{LxA}_{4}$, two molecules with hypothesised anti-inflammatory properties in patients with chronic lung diseases, was investigated. No evidence for a primary deficiency of these two mediators in $\mathrm{CF}$ lung disease was found, but evidence for a relative deficiency of CC-10 and $\mathrm{LxA}_{4}$ in CF patients with pronounced bronchial inflammation, as well as weak correlations between the content of CC-10 and $\mathrm{LxA}_{4}$, the granulocyte (PMN) count in BALF and the lung function of the subjects.

\section{Lipoxin $\boldsymbol{A}_{\boldsymbol{4}}$}

The present study revealed no absolute deficiency of $\mathrm{LxA}_{4}$ in $\mathrm{CF}$ patients. It was notable that the group of CF patients with pronounced inflammation, i.e. $>10 \%$ PMN in BALF, had PMN numbers that were $\sim 70$ times higher than the CF group with a low PMN count; the concentrations of $\mathrm{LxA}_{4}$ in BALF were the same. However, a relative deficiency in $\mathrm{LxA}_{4}$, expressed as the 

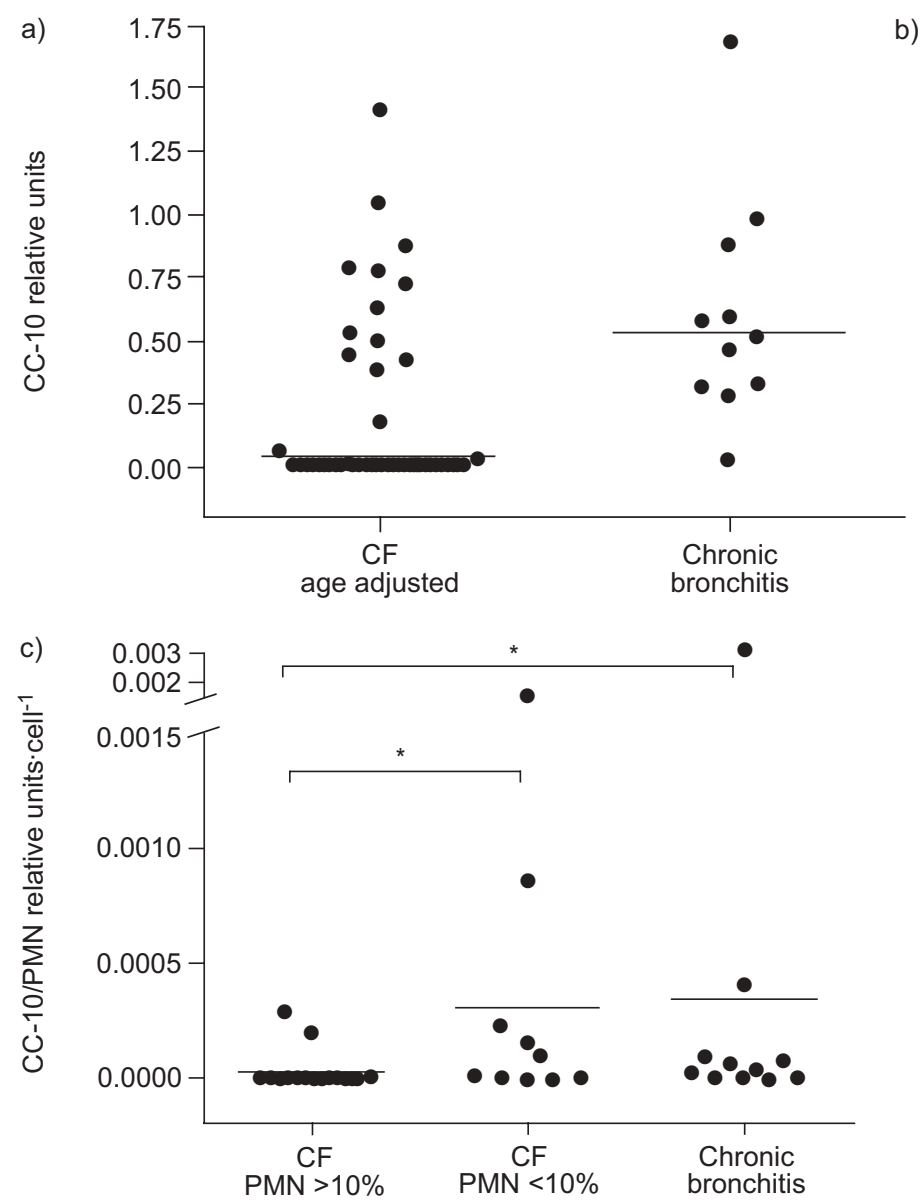

b)

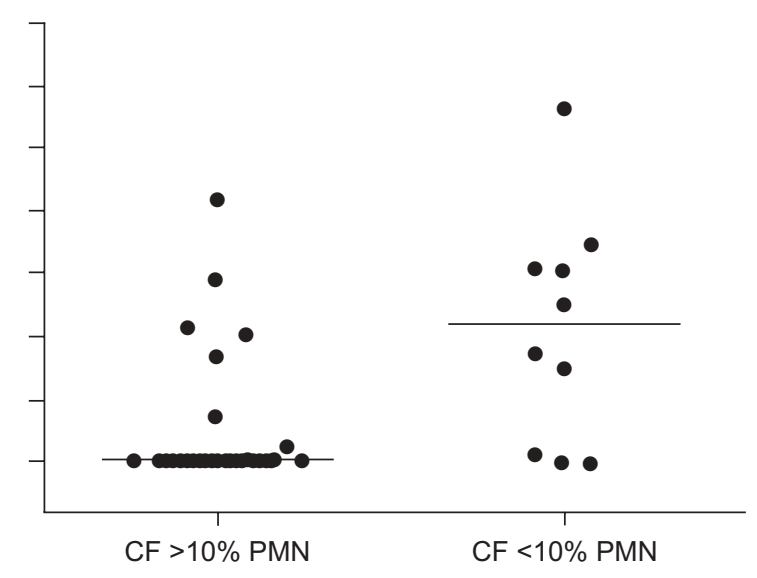

FIGURE 3. Clara cell protein (CC-10) content of bronchoalveolar lavage fluid (BALF). a) The content of CC-10 in BALF of age-adjusted cystic fibrosis (CF) patients was significantly lower than in the control disease group. b) Significantly lower levels of CC-10 were also found in CF patients with a high relative polymorphonuclear granulocytes (PMN) count $(>10 \%)$ in BALF in comparison with CC-10 content in BALF of CF patients with low relative PMN count (<10\%; Mann-Whitney U-test). c) The lowest values of CC-10/PMN ratio were also found in the group of CF patients with high relative PMN count ( $>10 \%$; Kruskal-Wallis test with Dunn's post hoc test). a) $p=0.041$; b) $p=0.037$. *: $p<0.05$.
$\mathrm{LxA}_{4} / \mathrm{PMN}$ ratio, was observed in $\mathrm{CF}$ patients with an elevated BALF PMN count. Together with a positive correlation between the number of PMNs and $\mathrm{LxA}_{4}$ concentration in BALF in the CF patients, it can be concluded that a relative lack of $\mathrm{LxA}_{4}$ may only be present in $\mathrm{CF}$ patients with marked inflammation. Unfortunately, the present authors were unable to find non-CF control subjects with the same degree of endobronchial inflammation as CF patients, and thus the present data do not allow a decision as to whether this phenomenon is specific for CF patients or is characteristic for any neutrophilic inflammation. Nevertheless, the data would not support the concept that lipoxin deficiency is a primary event in CF lung disease.

The in vitro and in vivo activities of $\mathrm{LxA}_{4}$ include: 1) inhibition of neutrophil chemotaxis, adherence and transmigration; suppression of neutrophil activation (including activation of the transcription factor nuclear factor- $\kappa \mathrm{B}$, superoxide generation and elastase secretion); 2) suppression of interleukin-8 production by epithelia and leukocytes; 3) upregulation of monocyte chemotaxis; 4) upregulation of monocyte ingestion of apoptotic neutrophils; 5) prevention of neutrophil-mediated damage; and 6) promotion of the resolution of neutrophilmediated inflammation [5]. Many of these factors, which can be influenced by $\mathrm{LxA}_{4}$, play a crucial role in the pathogenesis of lung damage in CF lung disease. The present data support the hypothesis that there is no primary deficiency of $\mathrm{LxA}_{4}$ in $\mathrm{CF}$, but deficiency can exist with respect to the relative production of $\mathrm{LxA}_{4}$ in $\mathrm{CF}$ patients with pronounced inflammation.

\section{Clara cell protein}

CF patients had lower levels of CC-10 than the patients with chronic bronchitis. At the same time, the most pronounced changes were found in CF patients with marked bronchial inflammation and levels of PMN $>10 \%$ in BALF, whereas CF patients with mild inflammation had the same content of CC10 as patients with chronic bronchitis. Taken together with the fact that there was a clear negative correlation between CC-10 content and the level of PMNs in the BALF, the conclusion may be drawn that a reduction of CC-10 in CF is a secondary phenomenon more likely to be associated with altered CC-10 production or secretion, damage to Clara cells or increased consumption of this protein. It is known that different environmental pollutants, including tobacco smoke, can lead to a decrease of the CC-10 content in BALF and serum CC-10 increases in acute or chronic lung disorders characterised by an increased airways permeability [18-20]. Decreased CC-10 concentrations in BALF are well described in acute lung injury [21]. The inflammatory response to lipopolysaccharide in the lung was associated with a marked reduction of CC-10 concentrations in BALF and lung homogenate, as well as of the CC-10 mRNA levels in the lung [22]. In serum, by contrast, the concentration of CC-10 was elevated, possibly as a consequence of increased airway permeability consistent with a marked reduction of secretion or synthesis of CC-10 [22]. In 

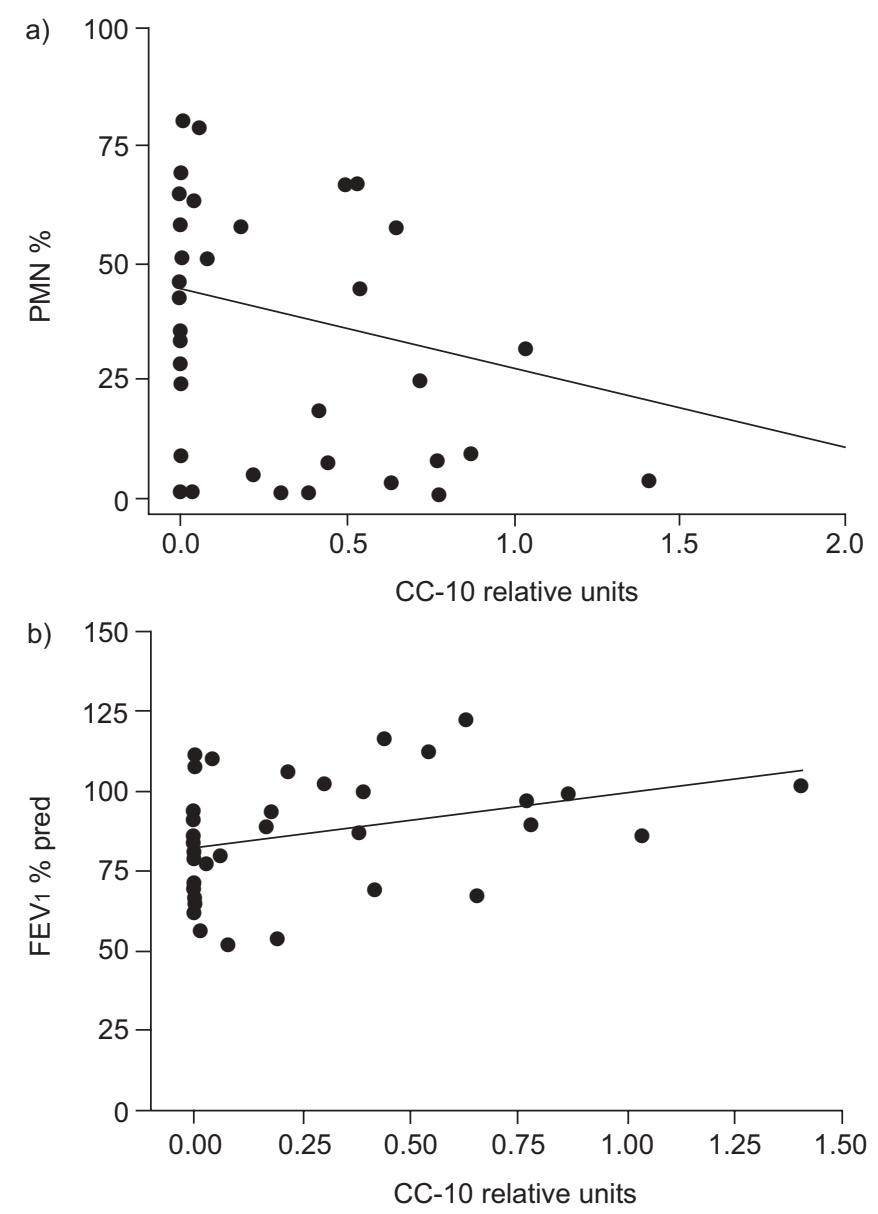

FIGURE 4. Correlations within the whole group of cystic fibrosis (CF) patients. a) Negative correlation between Clara cell protein (CC-10) content and relative polymorphonuclear granulocytes (PMN) count in bronchoalveolar lavage fluid (BALF) was found. b) There was a significant positive correlation between CC-10 BALF content and pulmonary function in CF patients (Spearman rank sum correlation test). FEV1: forced expiratory volume in one second. a) $r=-0.38, p=0.013 ; b) r=0.33 ; p=0.033$.

similar experiments, the lowest BALF CC-10 levels were detected in acute respiratory distress syndrome (ARDS) patients who eventually died [23]. In line with these results, a high concentration of CC-10, which also functions as a natural inhibitor of neutrophil function, decreased neutrophilmediated lung damage in patients with ARDS [24]. Decreased serum and BAL levels of CC-10 were also associated with bronchiolitis obliterans syndrome and airway neutrophilia in lung transplant recipients [25]. Therefore, the observed decrease in BALF CC-10 is unlikely to be a primary event, but rather the consequence of intense neutrophilic inflammation.

CC-10 has been proposed to function as an anti-inflammatory agent, based on its ability to inhibit the activation of PLA2, a key enzyme involved in the production of prostaglandins and other eicosanoids [11], and to inhibit thrombin-induced platelet aggregation and chemotaxis [26], as well as possessing antifibrotic activity $[12,27]$. The inflammatory, fibrotic and oncogenic phenotypes of a CC-10 knockout mouse illustrate the significance of preventing the initiation of these processes in vivo. In CC-10-deficient mice, the threshold for the initiation of these processes was significantly lowered, resulting in the exacerbation of inflammation in response to pulmonary insults $[28,29]$. The findings among CC-10-deficient mice demonstrate that the CC-10 -/- genotype results in more complex changes to airways than CC-10 deficiency per se [30]. Lung inflammation was significantly increased in CC-10 -/- mice compared with wild-type mice after infection. Importantly, restoration of CC-10 in the airways of CC-10 -/- mice abrogated increased viral persistence, lung inflammation and airway reactivity. These findings suggest a role for CC-10 and Clara cells in regulation of lung inflammatory and immune responses to infection [31].

Not much is known about the function of Clara cell protein in the lungs of patients with chronic lung diseases. The present findings of Clara cell protein deficiency in cystic fibrosis patients, accompanied by a corresponding decrease in pulmonary function, suggest impaired anti-inflammatory capacity of airway mucosa in these patients, which may be of importance for the development of chronic airway infection and inflammation. Strategies to increase natural antiinflammatory agents, and thus influence the disruption of the balance between natural inflammatory and anti-inflammatory or protective factors, could be useful to modulate tissue destruction and the course of chronic lung disease in cystic fibrosis.

\section{REFERENCES}

1 Bonfield TL. Inflammatory cytokines in cystic fibrosis lungs. Am J Respir Crit Care Med 1995; 152: 2111-2118.

2 Venkatakrishnan A, Stecenko AA, King G, et al. Exaggerated activation of nuclear factor-kappaB and altered IkappaB-beta processing in cystic fibrosis bronchial epithelial cells. Am J Respir Cell Mol Biol 2000; 23: 396-403.

3 Moss RB, Bocian RC, Hsu YP, et al. Reduced IL-10 secretion by CD4+ T lymphocytes expressing mutant cystic fibrosis transmembrane conductance regulator (CFTR). Clin Exp Immunol 1996; 106: 374-388.

4 Karp CL, Flick LM, Park KW, et al. Defective lipoxinmediated anti-inflammatory activity in the cystic fibrosis airway. Nat Immunol 2004; 5: 388-392.

5 Serhan CN. Lipoxins and aspirin-triggered 15-epi-lipoxin biosynthesis: an update and role in anti-inflammation and pro-resolution. Prostaglandins Other Lipid Mediat 2002; 6869: 433-455.

6 McMahon B, Mitchell S, Brady HR, Godson C. Lipoxins: revelations on resolution. Trends Pharmacol Sci 2001; 22: 391-395.

7 Lesur O, Bernard A, Arsalane K, et al. Clara cell protein (CC-16) induces a phospholipase A2-mediated inhibition of fibroblast migration in vitro. Am J Respir Crit Care Med 1995; 152: 290-297.

8 Boers JE, Ambergen AW, Thunnissen FB. Number and proliferation of Clara cells in normal human airway epithelium. Am J Respir Crit Care Med 1999; 159: 1585-1591.

9 Harrod KS, Mounday AD, Stripp BR, Whitsett JA. Clara cell secretory protein decreases lung inflammation after acute virus infection. Am J Physiol 1998; 275: L924-L930. 
10 Bernard A, Marchandise FX, Depelchin S, Lauwerys R, Sibille Y. Clara cell protein in serum and bronchoalveolar lavage. Eur Respir J 1992; 5: 1231-1238.

11 Chowdhury B, Mantile-Selvaggi G, Kundu GC, et al. Amino acid residues in alpha-helix-3 of human uteroglobin are critical for its phospholipase A2 inhibitory activity. Ann N Y Acad Sci 2000; 923: 307-311.

12 Pilon AL. Rationale for the development of recombinant human CC10 as a therapeutic for inflammatory and fibrotic disease. Ann N Y Acad Sci 2000; 923: 280-299.

13 Paul K, Rietschel E, Ballmann M, et al. Effect of treatment with dornase alpha on airway inflammation in patients with cystic fibrosis. Am J Respir Crit Care Med 2004; 169: 719-725.

14 Griese M, Ramakers J, Krasselt A, et al. Improvement of alveolar glutathione and lung function but not oxidative state in cystic fibrosis. Am J Respir Crit Care Med 2004; 169: 822-828.

15 Griese M, Birrer P, Demirsoy A. Pulmonary surfactant in cystic fibrosis. Eur Respir J 1997; 10: 1983-1988.

16 von Mutius E, Morgan WJ. Acute, chronic, and wheezy bronchitis. In: Taussig LM, Landau LI, eds. Pediatric Respiratory Medicine. Mosby, St Louis, 1999; pp. 547-556.

17 Morgan WJ, Taussig LM. The chronic bronchitis complex in children. Pediatr Clin North Am 1984; 31: 851-864.

18 Morimoto Y, Ding L, Oyabu T, et al. Expression of Clara cell secretory protein in the lungs of rats exposed to silicon carbide whisker in vivo. Toxicol Lett 2003; 145: 273-279.

19 Andersson O, Cassel TN, Skold CM, Eklund A, Lund J, Nord M. Clara cell secretory protein. Levels in BAL fluid after smoking cessation. Chest 2000; 118: 180-182.

20 Broeckaert F, Clippe A, Knoops B, Hermans C, Bernard A. Clara cell secretory protein (CC16): features as a peripheral lung biomarker. Ann N Y Acad Sci 2000; 923: 68-77.

21 Hermans C, Knoops B, Wiedig M, et al. Clara cell protein as a marker of Clara cell damage and bronchoalveolar blood barrier permeability. Eur Respir J 1999; 13: 1014-1021.

22 Arsalane K, Broeckaert F, Knoops B, Wiedig M, Toubeau G, Bernard A. Clara cell specific protein (CC16) expression after acute lung inflammation induced by intratracheal lipopolysaccharide administration. Am J Respir Crit Care Med 2000; 161: 1624-1630.

23 Jorens PG, Sibille Y, Goulding NJ, et al. Potential role of Clara cell protein, an endogenous phospholipase A2 inhibitor, in acute lung injury. Eur Respir J 1995; 8: 1647-1653.

24 Geerts L, Jorens PG, Willems J, De Ley M, Slegers H. Natural inhibitors of neutrophil function in acute respiratory distress syndrome. Crit Care Med 2001; 29: 1920-1924.

25 Nord M, Schubert K, Cassel TN, Andersson O, Riise GC. Decreased serum and bronchoalveolar lavage levels of Clara cell secretory protein (CC16) is associated with bronchiolitis obliterans syndrome and airway neutrophilia in lung transplant recipients. Transplantation 2002; 73: 1264-1269.

26 Lesur O, Bernard A, Arsalane K, et al. Clara cell protein (CC-16) induces a phospholipase A2-mediated inhibition of fibroblast migration in vitro. Am J Respir Crit Care Med 1995; 152: 290-297.

27 Manjunath R, Levin SW, Kumaroo KK, et al. Inhibition of thrombin-induced platelet aggregation by uteroglobin. Biochem Pharmacol 1987; 36: 741-746.

28 Johnston CJ, Finkelstein JN, Oberdorster G, Reynolds SD, Stripp BR. Clara cell secretory protein-deficient mice differ from wild-type mice in inflammatory chemokine expression to oxygen and ozone, but not to endotoxin. Exp Lung Res 1999; 25: 7-21.

29 Johnston CJ, Mango GW, Finkelstein JN, Stripp BR. Altered pulmonary response to hyperoxia in Clara cell secretory protein deficient mice. Am J Respir Cell Mol Biol 1997; 17: 147-155.

30 Stripp BR, Reynolds SD, Plopper CG, Boe IM, Lund J. Pulmonary phenotype of CCSP/UG deficient mice: a consequence of CCSP deficiency or altered Clara cell function? Ann N Y Acad Sci 2000; 923: 202-209.

31 Wang SZ, Rosenberger CL, Bao YX, Stark JM, Harrod KS. Clara cell secretory protein modulates lung inflammatory and immune responses to respiratory syncytial virus infection. J Immunol 2003; 171: 1051-1060. 